\title{
Ergonomics with a Human Face, a Pragmatic Perspective
}

\section{Badziili Nthubu*}

Department of Mechanical, Energy and Industrial Engineering, International University of Science and Technology, Botswana

\begin{abstract}
Ergonomics is the scientific field of knowledge concerned with the understanding of interactions between humans and systems or machines and furthermore the profession that applies theory, principles data and methods to design in order to optimize human well-being and overall system performance. Therefore, to further optimize the ergonomic performance the environment need to be incorporated in the human system interaction definition to form a tripartite symbiotic interphase. The purpose of this article is to discuss the role of ergonomists in improving the human, system and environmental conditions using the pragmatic approach of defining human factors ergonomics.
\end{abstract}

Keywords: Ergonomics; Economics; Health; Environment; Humans

\section{Introduction}

Dennerlein and Jack [1] describe ergonomics as the practice and research of the interaction between the human and the physical environment with the goal of optimizing human well-being and overall system performance. Further explains ergonomics as the scientific study of the relationship between man and his environment. The environment will include not only the conditions in which he is expected to work but also the materials and tools he uses. The field of ergonomics has been largely influenced by the drive to eliminate hazards in work areas and systems and to usher advances in technology in addressing areas of hazards and optimize safe and efficient operation of systems in the work place. The field has in no doubt improved the status quo in generating safe working environments for human, machine and the environment. Many often at times the human factors experts have addressed the issue of ergonomics with safety health and environment perspective.

In this article, we ask the same question, have we done enough as the global world to address issues surrounding the field of human factors? Humans are indeed a species which deserves to be protected at all times from obvious hazards posed by machines and systems created by the same humans. The vital responsibility remains with the ergonomist to create a symbiotic link between human operators and machine systems, not only the system but a smart web link to capture all evidence of risks and hazards associated with work to be conducted by humans. Currently the world stand at a time where during the design process effort is been made to bring elements of human factors as early as possible before embarking on the manufacture of any product or system, but still it has proved not to be enough.

Evidently, many authors such as to mention [2-6] but a few agree that ergonomic related incidences still remain to be largely a concern in developing and developed countries with the so called smart ergonomic systems in place. The evolution of ergonomics over the last 70 years has been largely influenced by the changes in science, engineering and technology; moreover, in agreement with the generational [5] changes in humans have also largely changed the previous assumptions and perceptions of how humans behave towards machines and systems.

Today we look at the world in a small perspective, we as humans have made efforts in making the world seem and look smaller to convince ourselves that we are in control, are we really in control of the world or it is in control of us as humans? In the west, engineers and scientists have conducted many experiments in the field to try and address problems associated with work areas but still we see disastrous accidents associated with human errors taking lives and destroying the environment [6]. The Japan Fukushima Daiichi nuclear disaster is a clear example of human failure to take ergonomic measures during the design phase of the project. It is the living evidence of human incapacity and the nature heavily capitalizing on our errors. The designers should have made efforts to make ergonomic models of the plant to cater for cases of tsunamis and ergonomically provide safety systems to suggest evacuations and relief if such eventualities may arise during the operations of the plant, in fact if we are in charge as humans we must engineer systems to eradicate chances of such disasters adversely affecting our systems.

In my view, negligence was mainly the cause of the incident on the part of designers to advice the constructors through design and or to advice the operators through operators manuals. These manuals are supposed to entail ergonomic procedures to primarily protect the humans involved during the life span of the plant. Therefore, ergonomics with the human face becomes vital. During the design phase, engineers and designers tend to take cognizant of production efficiency and pay little attention to human safety. But it is evident from past experience that safety can only be certain if ergonomic elements are considered at elementary stages of the project [2].

The Fukushima disaster resulted in the melt down of 3 of the 6 plant's nuclear reactors when it was hit by the Tsunami triggered by the Tohoku earth quake measuring a magnitude of 9.0 on the Richter scale. The plant subsequently released an amount of radioactive material becoming the largest nuclear incident since the Chernobyl disaster in 1986. In my view, any designer embarking on a project of a gigantic scale involving countries likely to be hit by disasters such as earthquakes must in no doubt consider ergonomics at the infant stages of the project. In agreement with my view point, Kim Vicente, a University of Toronto Professor of Ergonomics, argues that the nuclear disaster in Chernobyl is attributable to plant designers not paying enough attention to human factors. The role of ergonomics is to safeguard the humans who are irreplaceable, the environment

*Corresponding author: Badzili Nthubu, Department of Mechanical, Energy and Industrial Engineering, International University of Science and Technology, Botswana, Tel: +26775419697; E-mail: nthubu@yahoo.co.uk

Received June 30, 2017; Accepted July 24, 2017; Published July 28, 2017

Citation: Nthubu B (2017) Ergonomics with a Human Face, a Pragmatic Perspective. J Health Med Informat 8: 278. doi: 10.4172/2157-7420.1000278

Copyright: (c) 2017 Nthubu B. This is an open-access article distributed under the terms of the Creative Commons Attribution License, which permits unrestricted use, distribution, and reproduction in any medium, provided the original author and source are credited. 
which is also sometimes irreplaceable and, thirdly to safe guard the systems which are replaceable. The safety hierarchy of ergonomics can be demonstrated in Figure 1. Humans are at the top of the ergonomic hierarchy, cementing their place as the highest priority. The environment and systems around humans complement each other in the pursuit to protect the supreme humans who are indeed irreplaceable. Ironically, we as humans reconstruct the environment upon which to act or live, create systems and install them in the same environment upon which to operate. Therefore, we need make no mistake, the fact that we are at the top of the safety ergonomic hierarchy does not grant us the green light to disregard the ecosystem. The human minds recreate the environment and create systems. The insurmountable power vested in us provide humans with the opportunity to carefully consider fundamental laws to safe guard the environment and design eco-friendly systems to be used thereof.

During the reconstruction of the environment, many useful things are lost than gained, take for example during mining of diamonds in Botswana, using the open cast method, do humans involved in the excavations and burrowing of the land ever wonder how much they destroy the creatures that lay mutely beneath the soil. The prospects of diamond mining is brilliant, not to mention the volubility it brings to the betterment of the lives of many citizen Batswana people, who most vitally benefit from governmental aids and poverty eradication programmes propelled by the GDP from diamond revenues. The diamond revenue in Botswana contributes to more than $33 \%$ of the country's GDP making it the most significant source of revenue for Botswana [7].

But coming back to the issue of reconstruction of the environment to suit our personal gain, how often do we consider the damage we inflict on the environment, the ecosystem and all that is involved, very little compared to the value we place on reconstruction prospects. Globally, ergonomists are much less concerned with protecting the creatures of the soil, the originality of the landscape, the special species of the trees, grass, atmospheric pollutants, soundness of the forests and so forth. Their paramount concern is purported to be targeted at humans and systems to optimize them and achieve targeted productions and efficiency.

\section{Ergonomics from the Past}

What is human without the environment? And what is human and environment without systems? In other words in order for us to fully comprehend the human factors ergonomics of today, we must fully understand the relationship between these elements. Therefore, I define ergonomics as an organized philosophy which defines the relationship between human, environment and machines or systems, their working rapport to achieve a safe operating sphere for both elements. If we define ergonomics in these context, then there will be need to consider the safety of all the affected elements during the reconstruction of any environment at which we work.

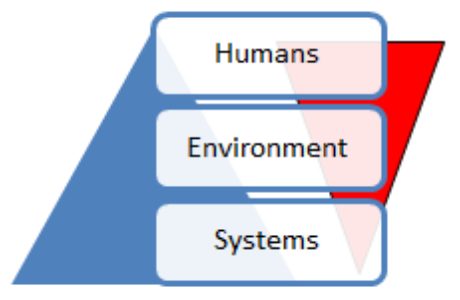

Figure 1: Safety hierarchy of ergonomics.
Even though ergonomics is believed by many to be a fairly new field of study in Botswana and or Africa as a whole, it is not entirely true, I grow up in the mists and shambles of rural and remote Botswana, where, even in the absence of modern machines, equipment and methods, the people had systems in place, they had machines in place as well as useful tools in place which in the contrary they considered modern. They considered their systems modern simply because they were also undergoing a technology evolution, comparing theirs with the generations before them. Most of these systems were ergonomically designed, with measurements to suit the average humans in those specific settlements. Even though one may argue that these people did not know how to read and write, well one does not need to know how to read and write to be able to measure someone's height and body weight, one does not need to know how to read and write to be able to determine the safe and unsafe sound, these people knew exactly how to consider human factors and environmental factors in their systems.

Take for example; in rural communities in Botswana, during the early 1980s, almost all rural communities were using cattle to plough as opposed to modern tractors. From an ergonomic point of view, there are more prospects of using cattle to plough compared to a modern tractor when considering issues of human factors or ergonomics. Firstly, we have to make note that ploughing in rural communities was and is still done on a small scale, an average family usually ploughs 1-3 hectors of land which requires 1-2 weeks of labour when using cattle compared to a few hours when using a tractor. However, when we come back to ergonomic implications of using a tractor, the driver sitting on the small tractor seat the whole day and been subjected to vibrations and sound of the tractor, not to mention the pollutants from the diesel exhaust fumes (Figure 2) and bumping up and down from the seat can affect the users [8-11] negatively as outlined by Shohne Daeijavad, C.R. Mehta, Roberto Deboli, C.R. Mehta.

Cattle ploughing from the ergonomic point of view made men and women athletic and healthy due to walking the whole day and using the whip to control the cattle as shown in Figure 3. The walking exercised the lower body and the upper body movements from flashing the whip in all directions. Noise pollutants are minimal or none existent. Therefore, ergonomics has long started with the episode of civilization in our societies; the only difference is that we did not call it ergonomics.

The application of ergonomics is also evident in ornaments and house hold equipment used even from the stone and wood age right through the Iron Age. Many African societies not long ago used wood as a raw material largely to produce utensils and furniture. They used stones and soil to build houses and make tools to perform work. They

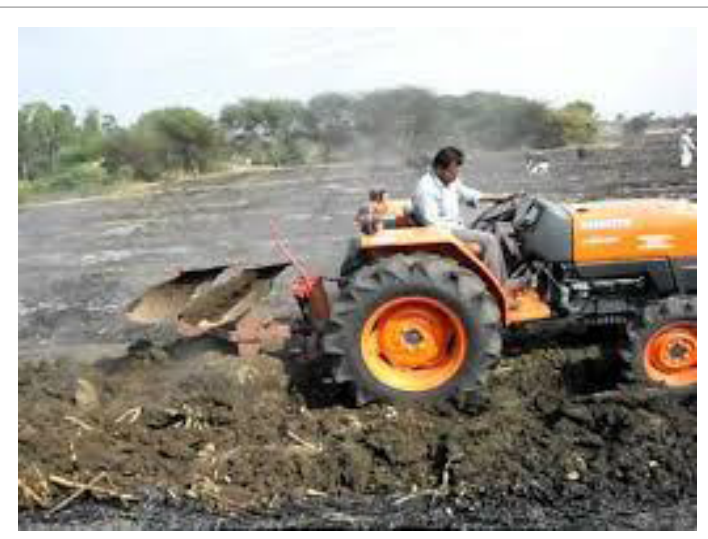

Figure 2: Tractor ploughing 

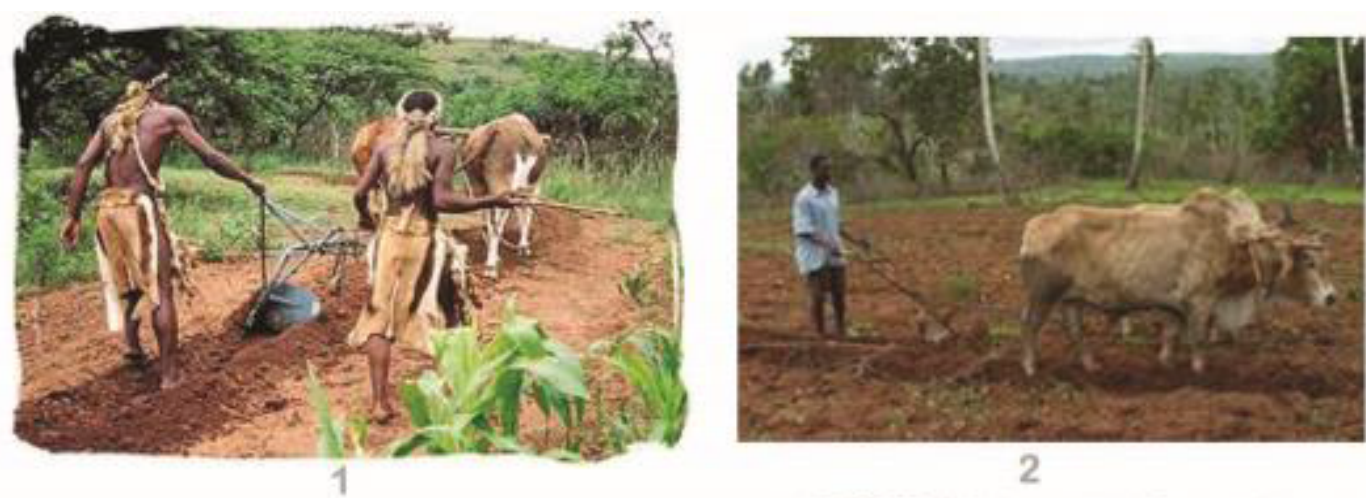

2
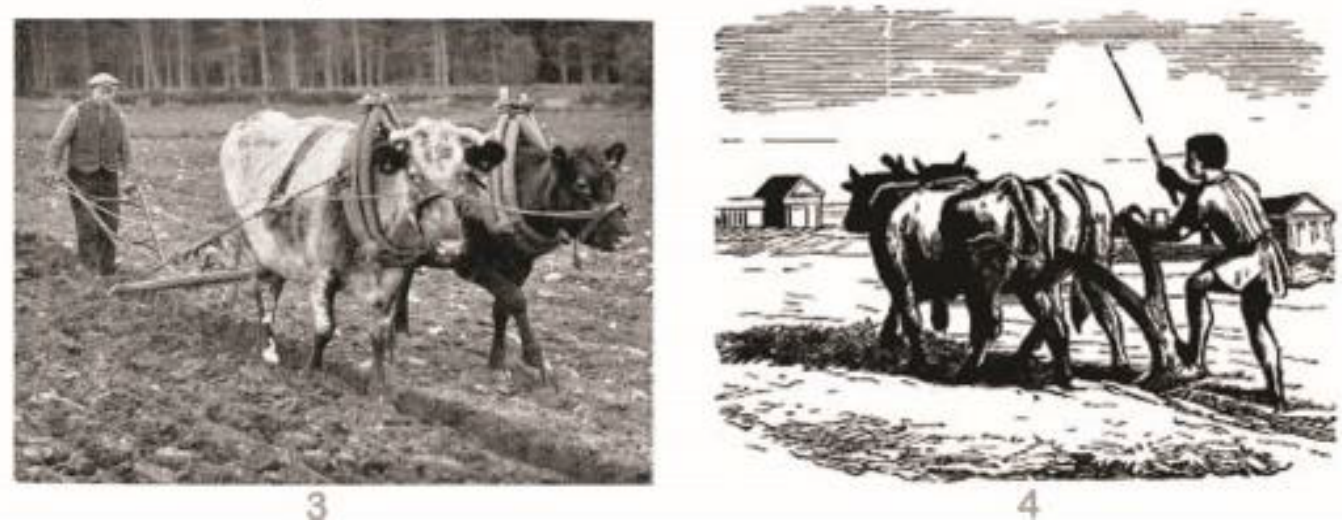

Figure 3: Cattle ploughing in Botswana and elsewhere.

build systems to process leather, wood, grass, food products such as sorghum, medicines, water, textiles etc. All these systems were designed with ergonomic consideration.

The question remains, have we reduced the number of muscular skeletal disorders from the old age to now? With the advent of technology, do we see the new age of industrialization free of MSDs? Perhaps we need to shift paradigm in the way we define ergonomics to largely concern humans at the expense of other elements. Perhaps we need to give all elements equal standing. I have convictions that it is possible to equal all players to balance the forces of nature hence the definition given earlier on.

Bridger [12] on his book, Introduction to ergonomics makes reference to the guiding philosophy of ergonomics known as "fitting the job to man" he advocates for designing work systems to be used by a large number of people irrespective of their physical differences. The author further explains that the philosophy works better as compared to fitting the man to job. In the past, FMJ came at a time when the demographics of the population of many settlements were different from today. There were many unskilled people and those holding positions were few and took long to be replaced unlike today were there are many graduates on the streets looking for jobs. FMJ was most suitable in the past than today. In my view, today we need a total approach paradigm to amalgamate inputs from the humans, environment and systems and harmonize their working relations. Proceeding of the international conference on ergonomics and human factors (2014), Southampton, UK, 7-10 April 2014, by Taylor \& Francis. Most of the scholars reiterated that an elaborate human, machine and environment interactions must be continually explored to provide solutions for the future.

\section{Ergonomics versus Economics}

It would be rather absurd to discuss ergonomics without stealing glances at economics because Schumacher in his book "Small is Beautiful, the study of economics as if people mattered" explains that economics in its entirety plays a central role in shaping the activities of the modern world, in as much as it supplies the criteria of what is economic and what is uneconomic, and there is no other set of criteria that exercises a greater influence over the actions of individuals and groups as well as over those of governments. Therefore economics take into cognizance the economic calculus which economists use the method of cost/benefit analysis. Under this formula, everything is equated with anything in terms of price and thus make the goods exchangeable to the extent that economic thinking is based on the market, it takes the sacredness out of life, because there can be nothing sacred in something that has a price. Furthermore, if economic thinking pervades the whole of society, even simple non-economic values like beauty, health and cleanliness can survive only if they prove to be economic, explained [13].

The link between the environment and ergonomics is varied by economics. Ergonomics seeks to provide a working rapport between the humans, environment and systems whereas economics looks at the profit viability of the activities conducted by humans using certain systems. More often than not the economists ignore the ergonomic prescriptions if such prescriptions are deemed uneconomic, which sometimes results in ergonomic related injuries. Taking the previous example of diamond mining in Botswana using the open cast method, from the economic point of view, the demands for diamonds propel the rate at which the excavations are handled and the methods used are somewhat geared towards the same demand. Even though safety and 
health issues are vital elements highly considered during mining, more emphasis is focused on demand and supply curve. Therefore, from the ergonomists point of view, the incident which took place in Jwaneng Diamond mine in June 2012, where the pit experienced a slope failure at cut 6 trapping 16 employees who were on night duty and later on rescuing 15 alive and 1 dead, is a clear example of negligence of ergonomic prescriptions on total ergonomic programs [14].

Many organizations around the world, particularly the production and manufacturing environments do not pay attention to ergonomic checklists, instead, they rather assume that the risk assessment covers every safety aspect which is not entirely true in my view and this is buttressed by Ya-Ju et al. [4]. It takes time and delays production to consider ergonomics during operation, ensuring ergonomic friendly environment before, during and after work takes a bit of time but at the end guarantees safe and efficient working environment which safeguard the workers, systems and the environment. A clear distinction between ergonomics and economics need be outlined and underlined.

In my view, the mining environment must have an elaborate safety framework and an elaborate ergonomic framework as well as economic framework. None of these frameworks must encircle the other in any fashion what so ever. The link between the three elements must be established and defined. It is rather economic and safe to have an economist, an ergonomist and a safety officer rather than an economist and a safety officer without an ergonomist and or an ergonomist and safety officer without an economist otherwise the business will meet its end prematurely. According to Figure 4, ergonomics appears at the beginning of the relations between the three elements to clearly demonstrate that everything, ranging from any activity of production, operations and manufacturing, it begins with the humans interacting with their tools and systems on their environment to achieve a certain goal. However the achievement of these goals must be done efficiently and safely to both elements involved. The ergonomic activities are mostly done to guarantee safety of the humans, systems and the environment. And finally we engage in all these activities obviously to generate profit and enhance the look and feel of our environment.

The dark horse which is the economist more often than not turn a blind eye to the other two elements, this I need say is not a personal attack on the field of economics, there is no doubt in my mind that it has brought about industrialization and civilization. However, thought must be engaged by these people in board rooms in other areas of interest such as ergonomics and how it implicates with the economics of production. Here is some of the ergonomic cost that economists must be fretful about as [15-17] outlined by Alexander:
- Medical and worker compensation costs.

- The expense of replacement workers.

- Lowered productivity.

- Lowered quality.

- Increases in supervisory costs.

- Overtime.

- Cost of turnover and training.

- Potential outside consultant fees.

- Potential regulatory fines.

In the absence of proper ergonomic frameworks and workflows, the danger of overlooking the above indirect costs associated with ergonomics is evident. More often than not, companies fail to justify work environment changes to suit ergonomic prescriptions simply because they do not know how to calculate the cost of these indirect costs and the economists end up not approving any ergonomic changes proposed. Therefore, companies should make efforts in ensuring that ergonomics is taken into consideration from the very first stage of designing a work environment. Alexander [18] has found that "lower design and construction costs can be obtained when equipment and facilities are designed right the first time. The cost of correcting ergonomic design at the initial part of a design project is about 10 percent of the cost that will occur later." Moreover, companies and organizations must remember that you can provide the worker with "ergonomically designed system" but if users are not adequately trained on how to use the features, they will remain fallow for a very long time. The ergonomically designed systems must be coupled with the development of a total ergonomic management program that includes training and development of users/employees.

\section{Impact of MSDs on Economies}

Muscular skeletal disorders form the major concern of many organizations across the globe because they proved to be reversing the prospects of production in many ways. The economists is most worried about this monster which is mostly linked to employees operating errors that subsequently result in substandard work quality and reduced operational productivity as [14] asserted by Graves. In 2002, MSDs accounted for 487,900 (34\%) of the injuries and illnesses in the U.S. involving days away from work [12]. From 1994 to 2002, the state of Washington estimated the cost of worker's compensation linked to MSDs to be $\$ 3.3$ billion [16]. The problem of MSDs is not synonymous to the USA alone, in UK for example, MSD risk factors can be found in virtually every occupation and work place [14].

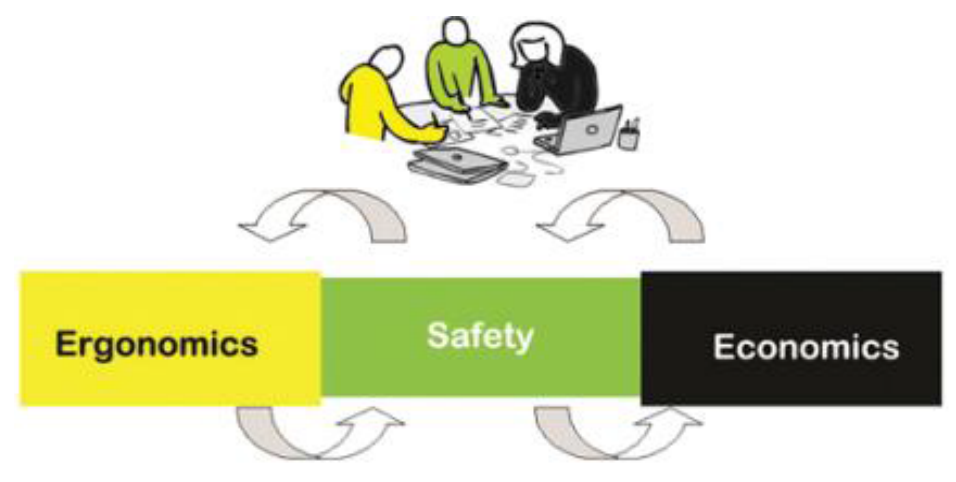

Figure 4: Illustration of the relation between the ergonomic, economic and safety. 
Even though the previous studies show that indeed the MSDs are mostly responsible for negating profit growth, managers and economists still remain sceptical about investment in managing MSDs in the work place. They still perceive the ergonomic type investment to be unnecessary expense rather than fiscally prudent investment intended to enhance business performance $[5,15,19-22]$, the greater task remains with the ergonomist to provide a compelling business case to management and economists/financial controllers.

\section{Conclusion}

The human face in scientific terms encompasses all the available human senses. Ergonomics as a field of knowledge can never be effective without the active participation of the human face. It is however possible to interface the human, systems and environment in cases where one of these senses is dysfunctional, even though it requires extra effort and budget. The five senses help the ergonomists to channel their knowledge in a much more effective way than otherwise [23-26].

Therefore, this article opens an opportune moment to interrogate the role of senses in implementing human face ergonomic programs. Ergonomics as defined earlier is the organized philosophy which defines the relationship between human, environment and machines or systems, their working rapport to achieve a safe and efficient operating sphere for both elements. When studying the five senses, our central point is the humans as one element of ergonomic hierarchy indicated earlier, in the past it was possible to design the job environment on the needs and physical dictates of one person as described by Robert Bridger [12], when explaining the philosophy of "Fitting the Man to Job (FMJ)". Under the circumstances surrounding work environment today, it is almost impossible to fit one man to work due to the mammoth size of the work force and large difference in stature. Therefore the only possible choice is use the philosophy of "Fitting the Man to Job (FMJ)". Job systems can be easily manipulated to be able to accommodate all visiting users hence the need to study the relationship between the senses and ergonomics, with deep understanding and comprehension of the relations, we will be able to interrogate the impact of the senses on the effectiveness of human, system and environmental interactions.

\section{References}

1. Jack T, Dennerlein T (2017) Ergonomics and musculoskeletal issues. In Encyclo Pub Healt 2: 577-584.

2. Veselinovic SP, Hedge A, Veselinovic M (2016) An ergonomic expert system for risk assessment of work related musculo-skeletal disorders. Int J Indus Ergonomic 53: 130-139.

3. Chander DS, Cavatorta MP (2017) An observation method for pastora ergonomics risk assessment (PERA). Int J Indus Ergonom 53:130-139.

4. Ya-Ju C, Nguyen D, Finkbeiner M, Kruger J (2016) Adapting ergonomics assessment to social life cycle assessment. Procedia CIRP 40: 91-96.

5. Parida R, Kumar-Ray $P$ (2015) Factors influencing construction ergonomics performance in India. Proc Manufact 3: 6587-6592.

6. Yuan $L$ (2015) Reducing ergonomic injuries for librarians using a participatory approach. Int J Indus Ergonomic 47: 93-103.
7. Beers D, Salterbaxter $G$ (2013) Operating and financial review report.

8. Daeijavad S, Maleki A (2016) Proper farm tractor seat angles for the right posture using FEM. Comput Electron Agri 124: 318-324.

9. Mehta CR, Tewari VK (2015) Biomechanical model to predict loads on lumbar vertebra of a tractor operator. Clin Biomech 47: 104-116.

10. Mehta CR, Tewari VK (2010) Damping characteristics of seat cushion materials for tractor ride comfort. J Terramech 47: 401-406.

11. Deboli R, Calvo A, Preti C (2017) Whole body vibration measurement of horizontal and vertical transmissibility of an agricultural tractor seat. Int $\mathrm{J}$ Indus Ergonomic 58: 69-78.

12. Bridger $R$ (2008) Introduction to ergonomics. CRC Press, USA.

13. Schumacher EF (1993) Small is beautiful, a study of economics as if people mattered. Vintage Publishing, UK.

14. Graves RJ, Way K, Riley D (2004) Development of risk filter and risk assessment worksheets for HSE Guidance: Upper limb disorders in the workplace. Appl Ergonomic 35: 475-484.

15. Wynn M (2003) Ergonomics ROI. Indus Eng 35: 43.

16. Hendrick HW (2003) Determining the cost-benefits of ergonomics projects and factors that lead to their success. Appl Ergonomic 34: 419-427.

17. Fletcher $M(2001)$ Ergo injury prevention programs reap big savings. Busin Insuranc 35: 54

18. Alexander DC (1998) Strategies for cost justifying ergonomic improvements IIE Solutions 30: 30-35.

19. Salvendy G (2012) Handbook of human factors and Ergonomics (4th edn.). John Wiley \& Sons, USA

20. Badziili N (2016) An ergonomic approach towards efficient and productive maintenance of fluidized bed heat exchangers (FBHEs) Morupule $\mathrm{B}$ Power Station. J Ergonomic 6: 167.

21. Roquelaure Y, Ha C, Leclerc A (2006) Epidemiologic surveillance of upperextremity muscular skeletal disorders in the working population. J Arthrit Car Res 55: 765-778.

22. Silverstein B, Adams D, Kalat J (2004) Work related musculoskeletal disorders of the neck, back and upper extremity in Washington State, 1994-2002.

23. Taylor T, Francis T (2014) Proceeding of the international conference on ergonomics and human factors.

24. Yeow PHP, Sen R (2003) Quality, productivity, occupational health and safety and cost effectiveness of ergonomic Improvements in the test of work stations of an electronic factory. Int J Indus Ergonomic 32: 147-163.

25. Watson JB, Rayner R (1920) Conditioned emotional reactions. J Exp Psych 3: 1-14.

26. Bernard Weerdmeester (2008) Ergonomics for beginners: A quick reference guide. CRC Press, USA. 